provided encouragement and advice. The study has been generously supported by the Arthritis and Rheumatism Council, and one of us (AF) has been in receipt of a grant from the Council.

\section{References}

${ }^{1}$ British Medical fournal, 1962, 2, 391.

2 Lancet, 1958, 1, 894.

${ }^{3}$ Fleming, A, et al, British Medical fournal. In press.

4 Jacoby, R K, Jayson, M I V, and Cosh, J A, British Medical fournal, 1973, 2, 96.

5 Metropolitan Life Assurance Company of New York, Statistical Bulletin, 1959, 40, 1.

${ }^{6}$ Duthie, J J R, et al, Annals of the Rheumatic Diseases, 1957, 16, 411.

7 Freyberg, R H, Medical Times, 1967, 95, 724.

${ }^{8}$ Duthie, J J R, et al, Annals of the Rheumatic Diseases, 1955, 14, 133.

9 Otten, H A, and Boerma, F W, Annals of the Rheumatic Diseases, 1959, 18,24 .
${ }^{10}$ Cecil, R L, and Archer, B H, fournal of the American Medical Association, 1926, 37, 741.

11 Short, C L, and Bauer, W, New England fournal of Medicine, 1948, 238, 142.

12 Bywaters, E G L, and Dresner, E, Quarterly fournal of Medicine, 1952, 21, 463.

13 Jonsson, E, Acta Orthopaedica Scandinavica, 1961, 30, 115.

14 Bywaters, E G L, Bulletin on Rheumatic Diseases, 1960, 11, 231.

15 Wawrzynska-Pagowska, J, et al, Acta Rheumatologica Scandinavica, 1970, 16, 99.

${ }^{16}$ Duthie, J J R, et al, Annals of the Rheumatic Diseases, 1964, 23, 193.

17 Short, C L, Bauer, W, and Reynolds, W E, Rheumatoid Arthritis. Cambridge, Mass, Harvard University Press, 1957.

18 Buckley, C W, Lancet, 1936, 1, 1023.

19 Steinbrocker, O, Fournal of the American Medical Association, 1946, 131, 189.

${ }^{20}$ Ragan, C, and Farrington, B S, fournal of the American Medical Association, 1962, 181, 663.

${ }^{21}$ Sharp, J T, et al, Medicine, 1964, 43, 41.

${ }^{22}$ Fleming, A, et al, Annals of the Rheumatic Diseases, in press.

\title{
Group B streptococci in the female genital tract
}

\author{
ROGER G FINCH, G L FRENCH, IAN PHILLIPS
}

British Medical fournal, 1976, 1, 1245-1247

\section{Summary}

Vaginal carriage rates of group B streptococci among 250 women attending a clinic for sexually transmitted diseases, 123 attending family planning clinics, and 110 in labour were $36.0 \%, 17 \cdot 1 \%$, and $6.4 \%$ respectively. The presence of group $B$ streptococci was not associated with a vaginal discharge or the use of oral contraceptives in the non-pregnant women, or with the isolation of Neisseria gonorrhoeae or Trichomonas vaginalis from the women attending the clinic for sexually transmitted diseases. Serotyping showed a predominance of types II and III in non-pregnant women and an overall incidence of nontypable strains of $14.8 \%$. There was no relationship between serotype and antibacterial susceptibility.

\section{Introduction}

Group B streptococci (Streptococcus agalactiae) are increasingly being recognised as a cause of serious perinatal infection, producing meningitis, septicaemia, or a fulminating pneumonitis, and as being associated with high mortality and morbidity rates. ${ }^{1-9}$ Studies have shown the importance of transmission from mother to infant either in utero or during parturition, ${ }^{2-410}$ although the possibility of nosocomially acquired infection from attendants ${ }^{11}$ has not been entirely excluded. There is also evidence that sexual transmission may be important. ${ }^{12}$

To try to establish the degree of risk of infection to the neonate and to examine the possibility of venereal transmission we assessed the vaginal carriage rates of group B streptococci in three categories of women: women in labour, women attending a clinic for sexually transmitted diseases (STD clinic), and women attending family planning clinics. In addition, all isolates were scrotyped and their susceptibilities to various antibacterial agents determined.

\footnotetext{
Department of Medical Microbiology, St Thomas's Hospital Medical School, London SE1 7EH

ROGER G FINCH, MB, MRCP, lecturer

G L FRENCH, BSC, $M B$, lecturer (present address: Department of Microbiology, University of the West Indies, Kingston, Jamaica)

IAN PHILLIPS, MD, MRCPATH, professor of microbiology
}

\section{Patients and methods}

The three categories of women were made up as follows: category 1 , 110 women in labour, with intact membranes, admitted nonconsecutively to the maternity department of St Thomas's Hospital; category 2, 123 women attending either of two family planning clinics, one at the Lambeth Hospital, London, and the other at a general practitioner clinic in Farnborough; and category 3, 250 non-pregnant, premenopausal women attending non-consecutively and for the first time the STD clinic at St Thomas's Hospital. Details on vaginal discharge and the use of oral contraceptives were obtained from women in categories 2 and 3, those in category 3 being examined for sexually transmitted diseases after the study sample had been obtained.

Under direct vision high vaginal samples were obtained on charcoalimpregnated swabs from the posterior or lateral fornices. No antibacterial or lubricating creams were used. The swabs were placed in Stuart's transport medium and processed within 16 hours by plating on Oxoid Columbia agar (Oxoid CM 331) containing 6\% horse blood, and on blood agar containing $0.0002 \%$ crystal violet and $0.08^{\circ}{ }_{0}$ chloral hydrate. The swabs were then placed in a liquid selective culture medium containing $5 \mathrm{ml}$ Todd-Hewitt broth $-8 \mathrm{mg}$ gentamicin and $15 \mathrm{mg}$ nalidixic acid per l-and incubated for 18 hours at $37^{\circ} \mathrm{C}$ in $10^{\circ}{ }_{0} \mathrm{CO}_{2}$. Subcultures were made from this medium to Columbia blood agar. All plates were incubated for 18 hours at $37^{\circ} \mathrm{C}$ in $10 \% \mathrm{CO}_{2}$ and examined for $\beta$-haemolytic colonies, which were then stained by Gram's method. All streptococcal isolates that failed to hydrolyse aesculin and ferment mannitol were then grouped by Lancefield's acid extraction method. ${ }^{13}$ Isolates of group B streptococci were serotyped at the Streptococcus Reference Laboratory, Colindale.

Finally, all isolates were examined for their susceptibility to benzylpenicillin, ampicillin, tetracycline, erythromycin, clindamycin, trimethoprim, sulphamethoxazole, gentamicin, and kanamycin by determining the minimum inhibitory concentrations (MICs). An inoculum of 10000 colony-forming units was used on diagnostic sensitivity test agar (Oxoid CM 261) containing $6 \%$ lysed horse blood and appropriate concentrations of antibacterials and incubated aerobically for 18 hours at $37^{\circ} \mathrm{C}$. MICs were read as the smallest amount of antibacterial producing complete or almost complete inhibition of growth.

\section{Results}

Table I shows the isolation rates of group B streptococci in the three categories of women. There was no statistically significant association between the presence of group B streptococci and either a vaginal discharge or the use of oral contraceptives in categories 2 and 3 , or the isolation of Neisseria gonorrhoeae or Trichomonas vaginalis in category 3. 
TABLE I-Isolation rates of group B streptococci in three categories of women

\begin{tabular}{|c|c|c|c|c|}
\hline \multirow[t]{2}{*}{ Category } & \multirow[t]{2}{*}{$\begin{array}{c}\text { No } \\
\text { tested }\end{array}$} & \multicolumn{2}{|c|}{$\begin{array}{l}\text { Proportion } \\
\text { positive for } \\
\text { group B } \\
\text { streptococci }\end{array}$} & \multirow{2}{*}{$\begin{array}{c}\text { Significance of } \\
\text { difference between } \\
\text { categories* }\end{array}$} \\
\hline & & No & $\%$ & \\
\hline \multirow{3}{*}{$\begin{array}{l}1 \text { (Women in labour) } \\
2 \text { (Women attending family } \\
\text { planning clinics).. } \\
3 \text { (Women attending STD } \\
\text { clinic) }\end{array}$} & 110 & 7 & $6 \cdot 4$ & \multirow{3}{*}{$\begin{array}{l}\text { Categories } 1 \text { and } 2: \\
P<0.01 \\
\text { Categories } 2 \text { and 3: } \\
P<0.0005 \text { and } \\
\text { Categories } 1 \text { and 3: } \\
P<0.0001\end{array}$} \\
\hline & 123 & 21 & $17 \cdot 1$ & \\
\hline & 250 & 90 & $36 \cdot 0$ & \\
\hline Total & 483 & 118 & $24 \cdot 4$ & \\
\hline
\end{tabular}

*Significance was calculated with the use of Yates's modification for small numbers.

TABLE II-Distribution of group B streptococcal serotypes in the three categories of women

\begin{tabular}{|c|c|c|c|c|c|c|}
\hline \multirow{2}{*}{ Category } & \multicolumn{5}{|c|}{ Serotype } & \multirow{2}{*}{ Total } \\
\hline & Ia & Ib & II & III & $\mathrm{NT}^{*}$ & \\
\hline $\begin{array}{l}1 \\
2 \\
3\end{array}$ & $\begin{array}{l}2 \\
2 \\
9\end{array}$ & $\begin{array}{r}2 \\
12\end{array}$ & $\begin{array}{r}1 \\
9 \\
15\end{array}$ & $\begin{array}{r}1 \\
45\end{array}$ & $\begin{array}{l}1 \\
7 \\
9\end{array}$ & $\begin{array}{c}7 \\
18^{+} \\
90\end{array}$ \\
\hline
\end{tabular}

*Non-typable strains.

tThree isolates died before serotyping could be carried out.

The results of serotyping are given in table II; three isolates died before they could be serotyped.

Table III shows the MICs of the antibacterials tested against group B streptococci, and table IV the MICs of sulphamethoxazole and trimethoprim both separately and in combination. The fractional inhibitory concentrations (FICs) ${ }^{14}$ of sulphamethoxazole and trimethoprim were determined and the summed results calculated to confirm that the combination was synergistic. (The FIC is defined as the MIC of the agent in combination divided by the MIC of the agent used alone. ${ }^{14}$ ) Analysis of the MICs of the various antibacterials failed to show any relationship between susceptibility and serotype.

\section{Discussion}

Because the heavy work load made it impossible to examine all patients attending the various clinics specimens were inevitably non-consecutive; in all other respects, however, they were unselected.

The use of a selective culture medium to suppress the normal vaginal flora and allow the growth of streptococci yields higher isolation rates than the use of conventional, unselective media. ${ }^{15}$ In a pilot study of 100 samples from women attending the STD clinic in which the selective medium was not used an isolation rate of $20 \%$ was found; this differs significantly from the isolation rate of $36^{\circ} \%$ found in the present study, in which the selective medium was used $(P<0.01)$. In addition, all streptococci isolated in the pilot study were tested for the frequency of $\alpha$-haemolytic or non-haemolytic strains of group B streptococci but none was found. We therefore decided to study only $\beta$-haemolytic streptococcal isolates.

The difference in carriage rates between the three categories of women studied is statistically significant. The rate of $36 \%$ among the women attending the STD clinic (category 3) is
TABLE IV-Distribution of minimum inhibitory concentrations (MICs) of sulphamethoxazole and trimethoprim alone and in combination (ratio 20:1) for 76 strains of group $B$ streptococci

\begin{tabular}{|c|c|c|c|}
\hline \multirow[b]{2}{*}{$\underset{(\mathrm{mg} / \mathrm{l})}{\mathrm{MIC}}$} & \multicolumn{3}{|c|}{ No of strains sensitive to: } \\
\hline & Sulphamethoxazole & Trimethoprim & $\begin{array}{l}20 \text { Parts } \\
\text { sulphamethoxazole, } \\
1 \text { part trimethoprim* }\end{array}$ \\
\hline $\begin{array}{l}0.12 \\
0.25 \\
0.5 \\
1 \\
2 \\
4\end{array}$ & $\begin{array}{r}1 \\
10 \\
46 \\
19\end{array}$ & $\begin{array}{r}5 \\
54 \\
14 \\
1 \\
2\end{array}$ & $\begin{array}{r}2 \\
24 \\
35 \\
14 \\
1\end{array}$ \\
\hline
\end{tabular}

*For example, sulphamethoxazole $0.12 \mathrm{mg} / 1$ with trimethoprim $0.006 \mathrm{mg} / 1$.

particularly striking, and is the highest to be recorded. Among 364 women attending a similar clinic in Sweden the isolation rate from cervical samples was $11 \cdot 5^{\circ}{ }_{0} .^{12}$ Sexual transmission may be important in the epidemiology of group B streptococci since they have been isolated from both male ${ }^{12}$ and female ${ }^{12}$ urethras.

The isolation rate of $17 \cdot 1^{\circ}$ o among women attending family planning clinics (category 2) is of interest. These women were sexually active but presumed to be less promiscuous. A more detailed study would be necessary, however, before any firm conclusions could be drawn.

Vaginal carriage rates of group B streptococci in pregnancy have ranged from $2 \cdot 3^{\circ}$ to $25 \cdot 4^{\circ} \%^{1} 241116$ The rate of $25 \cdot 4^{\circ} \%$ was obtained among women at term by Baker and Barrett ${ }^{11}$ in the USA using a selective culture medium. Our carriage rate of $6.4 \%$ among women in labour (category 1 ), using a similar selective culture medium, differs significantly $(P<0.0006)$ from theirs, which may result from behavioural or geographical differences. The carriage rate of $6.4 \%$ among our category 1 women also differed significantly from the rates among the other categories of women we studied.

Serotyping showed a predominance of types II and III in the non-pregnant women (categories 2 and 3), which agrees with the yndings of Franciosi et al, ${ }^{1}$ who also showed an increasing prevalance of type I strains as pregnancy advances. Our overall incidence of non-typable strains of $14.8 \%$ is higher than in other studies; all but one isolate occurred in non-pregnant women. Non-typable strains rarely cause infection and have produced only two reported cases of neonatal meningitis ${ }^{17}$ in the past five years in England and Wales. The importance of serotyping has been emphasised by the association of type I strains with a usually fatal septicaemic illness of early onset accompanied by respiratory distress occurring at birth or developing within a few hours after delivery, and type III with a later-onset meningitic illness and a lower mortality rate of $45 \%$. $^{1}$

The MICs of the antibacterials tested against group $B$ streptococci were similar to those reported by Matsen and Coughlan. ${ }^{18}$ The strains tested showed a similar distribution of MICs for both benzylpenicillin and erythromycin. Susceptibility to tetracycline was bimodally distributed, with $74 \%$ of strains appearing resistant. Apart from three strains sensitive to gentamicin, one of which was also sensitive to kanamycin, all isolates were resistant to both gentamicin and kanamycin. The isolates were sensitive to sulphamethoxazole, and all but three gave MICs of $1 \mathrm{mg} / 1$ or less with trimethoprim. The sum of the

\begin{tabular}{|c|c|c|c|c|c|c|c|c|c|c|c|c|c|c|c|c|c|c|c|c|}
\hline \multirow[b]{2}{*}{ - } & & & & \multicolumn{16}{|c|}{ Minimum inhibitory concentration (mg/l) } & \multirow{2}{*}{$\begin{array}{l}\text { Total } \\
\text { No of } \\
\text { strains }\end{array}$} \\
\hline & & & & 0.01 & 0.03 & 0.06 & $0 \cdot 12$ & $0 \cdot 25$ & 0.5 & 1 & 2 & 4 & 8 & 16 & 32 & 64 & 128 & 256 & 512 & \\
\hline $\begin{array}{l}\text { Benzylpenicillin. } \\
\text { Ampicillin }\end{array}$ & $\begin{array}{l}\cdots \\
\cdots \\
\cdots \\
\cdots \\
\cdots\end{array}$ & $\begin{array}{l}\ldots \\
\cdots \\
\cdots \\
\cdots \\
\cdots\end{array}$ & $\begin{array}{l}\cdots \\
\cdots \\
\cdots \\
\cdots \\
\cdots \\
\cdots\end{array}$ & $\begin{array}{r}9 \\
1 \\
10\end{array}$ & $\begin{array}{r}119 \\
\\
51 \\
19\end{array}$ & $\begin{array}{r}4 \\
76 \\
6 \\
14 \\
55\end{array}$ & $\begin{array}{c}55 \\
19 \\
1^{*}\end{array}$ & 1 & 1 & 1 & $1+$ & $\begin{array}{l}2 \\
1\end{array}$ & 1 & 32 & 31 & 6 & 12 & 50 & 7 & $\begin{array}{r}132 \\
132 \\
132 \\
76 \\
76 \\
72 \\
72\end{array}$ \\
\hline
\end{tabular}

${ }^{*} \mathrm{MIC}>0 \cdot 12 \mathrm{mg} / \mathrm{l} . \quad+\mathrm{MIC}>2 \mathrm{mg} / \mathrm{l}$. 
FICs for trimethoprim and sulphamethoxazole showed the combination to be synergistic for all but one strain. There was no relationship between MIC and serotype. In our experience group $B$ streptococci are four times less sensitive to ampicillin than are group A streptococci, but are equally susceptible to erythromycin and clindamycin. Whether these differences are important in the treatment of vaginal carriage needs further study, although penicillin effectively eradicated group B streptococci from the vagina in 13 out of 14 women in one series. ${ }^{1}$

Our study shows a high prevalence of group B streptococci in the vagina of sexually active, non-pregnant women, in whom it is unassociated with clinical evidence of infection. Although the prevalence appears to be much less in women in labour, the potential for serious perinatal infection must be considered. Screening of all women in labour, or possibly in late pregnancy, for group B streptocci is a possibility. Knowledge that the woman harbours the organism should alert the clinician to the risk to the child. Benzylpenicillin shows the greatest activity against the group B streptococcus in vitro and remains the drug of choice for established infection. On the other hand, prophylactic administration of penicillin to the mother carrying group $B$ streptococci has been advocated in view of the fulminating nature of the septicaemic infection in the neonate. ${ }^{19}$ Others, however, argue strongly against this. ${ }^{20}$ If the carriage rate among pregnant women at term is assumed to be $6 \%$, then with about 675000 live births a year ${ }^{21}$ some 40000 women would be eligible for a course of penicillin in England and Wales if it were shown effectively to eradicate carriage. The risks of serious side effects would be considerable. An alternative might be to protect by chemoprophylaxis the 40000 at-risk infants born to women known to be harbouring group $B$ streptococci at the time of delivery, or to include only those born prematurely ${ }^{7}$ or with congenital abnormalities ${ }^{5}$ and those in whom there was some complication of labour such as prolonged rupture of the membranes. ${ }^{7}$ Attack rates, however, are considerably smaller than isolation rates. At St Thomas's Hospital we have had only seven cases of group B neonatal sepsis in the past five years; with a delivery rate of about 1300 a year, this gives an incidence of 1 in 900 deliveries. If $6 \%$ of pregnancies are assumed to be at risk then our attack rate is approximately $1.8 \%$, which is similar to that found in other studies. ${ }^{11}$
A policy of close surveillance of neonates born to mothers known to be harbouring the organism at the time of labour, the prompt taking of bacteriological samples for culture, and adequate early treatment appears to be a rational approach to the problem of group B streptococcal infection in the neonate until more information on its pathogenesis and epidemiology becomes available.

We thank the medical and nursing staff of Lydia department and Mary wards, St Thomas's Hospital, and also Dr J N Kayll for their help and co-operation in collecting specimens. We are also grateful for the help of the Streptococcus Reference Laboratory, Colindale, in serotyping the strains.

\section{References}

1.Franciosi, R A, Knostman, J D, and Zimmerman, R A, fournal of Pediatrics, 1973, 82, 707.

${ }^{2}$ Hood, M, Janney, A, and Dameron, G, American fournal of Obstetrics and Gynecology, 1961, 82, 809.

${ }^{3}$ Keital, H G, et al, fournal of Pediatrics, 1962, 61, 39.

4 Butter, M N W, and de Moor, C E, Antonie van Leeuwenhoek, 1967, 33, 439.

${ }^{5}$ Bergqvist, G, et al, Scandinavian fournal of Infectious Diseases, 1971, 3, 157.

6 Nyhan, W L, and Fousek, M D, Pediatrics, 1958, 22, 268.

${ }^{7}$ Eickhoff, T C, et al, New England fournal of Medicine, 1964, 271, 1221.

8 Jones, H E, and Howells, C H L, Postgraduate Medical fournal, 1968, 44, 549.

${ }^{9}$ Harper, I, fournal of Clinical Pathology, 1971, 24, 438

10 Baker, C J, et al, fournal of Pediatrics, 1973, 82, 724

${ }_{11}$ Baker, C J, and Barrett, F F, fournal of Pediatrics, 1973, 83, 919.

12 Christensen, K K, et al, Acta Pathologica et Microbiologica Scandinavica, section B, 1974, 82, 270.

13 Lancefield, R C, Fournal of Experimental Medicine, 1933, 57, 571.

${ }_{1 \mathrm{~b}}$ Bushby, S R N, Postgraduate Medical fournal, 1969, 45, Nov suppl, p 10. Baker, C J, Clark, D J, and Barret, F F, Applied Microbiology, 1973, 26, 884.

${ }^{16}$ Lancefield, R C, and Hare, R, Fournal of Experimental Medicine, 1935, 61, 335.

17 Parker, M T, personal communication

${ }_{18}$ Matsen, J M, and Coughlan, C R, in Streptococci and Streptococcal Disease, ed L W Wannamaker and J M Matsen, p 193. New York and London, Academic Press, 1972.

19 McCraken, G H, Fournal of Pediatrics, 1973, 82, 703.

${ }^{20}$ Eickhoff, T C, et al, fournal of Pediatrics, 1973, 83, 1097.

${ }^{21}$ Registrar General, Statistical Review of England and Wales for the Year 1973. London, HMSO, 1975.

\title{
Evidence for familial immune defect in meningococcal meningitis
}

\author{
H C WHITTLE, A ODULOJU, G EVANS-JONES, B M GREENWOOD
}

British Medical fournal, 1976, 1, 1247-1250

\section{Summary}

Twenty-six patients who had recovered from group A meningococcal meningitis were vaccinated with group $\mathbf{C}$ meningococcal polysaccharide and tetanus toxoid. Their

\footnotetext{
Departments of Medicine and Paediatrics, Ahmadu Bello University Hospital, Zaria, Nigeria

H C WHITTLE, MRCP, senior lecturer in medicine

A ODULOJU, FIMLT, senior technologist

G EVANS-JONES, MRCP, senior registrar in paediatrics

B M GREENWOOD, MRCP, senior lecturer in medicine
}

\begin{abstract}
haemagglutinating antibody response was measured two weeks later and compared with those of 22 siblings and 39 controls. Patients and siblings had a significantly lower antibody response to the group $C$ vaccine but not to tetanus toxoid. This suggests that patients susceptible to meningococcal disease may have an immune defect involving their response to meningococcal polysaccharides.
\end{abstract}

\section{Introduction}

Meningococcal meningitis is an infrequent complication of Neisseria meningitidis infection, and even in epidemics most people exposed to the pathogenic strain become asymptomatic carriers. ${ }^{1}$ In certain families during such outbreaks, however, 